\title{
Working while sick: validation of the multidimensional presenteeism exposures and productivity survey for nurses (MPEPS-N)
}

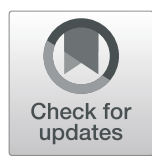

Juliana Nga Man Lui and Janice Mary Johnston ${ }^{*}$ (]

\begin{abstract}
Background: Presenteeism is the employee behaviour of physically attending work with reduced performance due to illness or for other reasons. Nurses are four times more likely to exhibit presenteeism compared to other occupations, threatening patient safety through increased patient falls, medication errors and staff-to-patient disease transmission. There is a paucity of standardized instruments that quantify the association between presenteeism with its exposures and related productivity. This study aims to validate an instrument that comprehensively measures presenteeism workplace and personal exposures specifically for Asian nurses.

Methods: Questionnaire domain items were selected based on the JD-R framework and a previously conducted systematic review of pre-existing validated scales measuring work attendance exposures used in previous healthcare studies. The preliminary questionnaire consisted of two outcomes (presenteeism frequency, productivity) and five exposure domains: work resources, work demands, work stress, work engagement, personal traits and health.

Content validation and back translation (English-Cantonese Chinese-English) were carried out. Responses from fulltime nurses working in two acute care hospitals (Preliminary questionnaire at Hospital 1: N=295 and main round questionnaire at Hospital 2: $N=1146$ ) were included in the validation study to ensure an adequate sample size of ten cases per indicator variable for CFA analysis. A random sample of 80 nurses from Hospital 1 were selected for test-retest reliability 4 weeks post the initial survey. Internal consistency, convergent and discriminant validity tests were also tested.
\end{abstract}

Results: Satisfactory internal consistency (Cronbach's alpha $>0.7$ ), test-retest reliability (ICC $>0.4)$; and construct validity - convergent and discriminant validity was achieved. Confirmatory factor analysis yielded satisfactory fitness indices (CFI and TLI > 0.95, RMSEA < 0.08). Presenteeism and productivity significantly associated with all work resources, work engagement and work stress constructs in Hospital 2.

Conclusion: A reliable Multidimensional Presenteeism Exposures and Productivity Survey (MPEPS-N) has been validated in two distinct hospital environments. The instrument helps to identify and quantify organizational or individual exposures that significantly associate with presenteeism and its related productivity, thus allowing hospital managers to set evidence-based intervention targets for wellness programs and formulate human resource policies in reducing presenteeism-related productivity loss.

Keywords: Human resource management, Presenteeism, Job demands and resources, Work stress, Work engagement, Productivity, Nurse

\footnotetext{
* Correspondence: jjohnsto@hku.hk

School of Public Health, Li Ka Shing Faculty of Medicine, The University of

Hong Kong, G/F Patrick Manson Building (North Wing), 7 Sassoon Road,

Pokfulam, Hong Kong, Special Administrative Region of China
}

(c) The Author(s). 2019 Open Access This article is distributed under the terms of the Creative Commons Attribution 4.0 International License (http://creativecommons.org/licenses/by/4.0/), which permits unrestricted use, distribution, and reproduction in any medium, provided you give appropriate credit to the original author(s) and the source, provide a link to the Creative Commons license, and indicate if changes were made. The Creative Commons Public Domain Dedication waiver (http://creativecommons.org/publicdomain/zero/1.0/) applies to the data made available in this article, unless otherwise stated. 


\section{Background}

To maintain a sustainable workforce in face of increasing employer-borne healthcare costs, management experts in recent years have sought ways to reduce indirect employee healthcare expenses such as absence replacement and related productivity loss costs [1-3]. Earlier employee health productivity costing studies considered only direct healthcare expenses and sickness absence costs $[4,5]$, however a study reported that indirect presenteeism illness-related productivity loss costs were found to be 11.5 times higher than direct medical costs of taking sick leave [6].

Presenteeism is the employee behaviour of physically attending work with reduced performance due to illness or for other reasons [7]. Productivity is the performance measure of efficiency and effectiveness of employees when they are at work [8], where productivity may be limited by employee health conditions at work such as presenteeism. Nurses are four times more likely to work while sick compared to other health care or social welfare workers [9]; such behavior is shown to impact patient safety through increased patient falls, medication errors and staff-to-patient disease transmission [10, 11]. As nurses constitute the largest proportion of paid healthcare workforce [12], their productivity, healthcare and welfare costs constitute a substantial portion of hospital expenses, healthcare researchers started to gain interest in nurse presenteeism research [10, 13-15].

Available presenteeism instruments measure frequency of sickness presenteeism episodes [9], presenteeism-related productivity loss and related costs (estimated by employee's salary discounted by self-rated on-the job productivity levels reductions) [16-18], and employee health and related medical costs $[1,19]$. However, existing measures focus on estimating the impact of presenteeism (organizational productivity or monetary loss) but not helpful in identifying evidence-based human resources intervention targets to reduce presenteeism. As suggested in our systematic review on presenteeism exposures and outcomes amongst hospital doctors and nurses [20], despite attempts to carry out studies on the association between presenteeism and its work-related exposures by healthcare researchers [13, 21, 22], the heterogeneity, limited quality of selected measurement tools and paucity in theoretical framework adoption in studies restrict systematic investigation and generalizability of findings, limiting further research progress on management intervention targets in reducing nurse presenteeism [20]. Thus, a questionnaire based on a common theoretical framework with standardized valid and reliable measures on psychometric-related presenteeism exposures is needed.

This study is based on the Jobs Demands-Resources (JD-R) model, a popular framework for nurse organizational behavioural studies [20]. JD-R hypothesizes a bidirectional nature /dual process pathway between work resources (e.g., task significance, work schedule, social support, social feedback and organizational care, rewards) and work demands (e.g., physical demands, team psychological demands, effort and ease of substitution) on employee psychosocial emotions (work engagement and work stress), leading to downstream employee outcomes (presenteeism and productivity) [23] (Fig. 1). Other than work-related factors, personal health and traits (e.g. health locus of control) were postulated to impact presenteeism and thus is included in our research framework [2, 24-26].

In Asia, nurses more commonly face acute manpower shortages, high patient to bed ratios and not infrequently large-scale infectious disease outbreaks [27-29]. Asian nurses, perhaps influenced both by work related and societal culture (more collectivist than in the west) are more prone to exhibit presenteeism, which may lead to long term health issues and high turnover rates [30, 31]. More culturally relevant organizational and employee related behavioural research is needed to inform the management and human resources policies and strategies necessary to reach pareto optimality (e.g., allocating limited resources to achieve maximized productivity) is required [31, 32].

This study aims to validate the Multidimensional Presenteeism Exposures and Productivity Survey for Nurses (MPEPS-N) to support the comprehensive measurement of workplace presenteeism and exposures among Asian nurses.

\section{Methods}

\section{Questionnaire development}

The MPEPS-N validation procedure timeline is listed in Fig. 2. In the first step, presenteeism exposure domain items, informed by a previously conducted systematic review [20], from which pre-existing validated scales measuring attributes of work attendance previously used in previous JD-R model studies amongst hospital frontline healthcare professionals (nurses and doctors) were extracted.

\section{Measures}

Some of the selected items $[9,33]$ or scales in the Multidimensional Presenteeism Exposures and Productivity Survey for Nurses (MPEPS-N) such as work design questionnaire (WDQ) [34], Nordic Psychological \& Social Factors at Work (QPS Nordic) [35], Dutch Musculoskeletal Questionnaire [36] do not have validated Chinese versions (Table 1). Whereas Effort-reward imbalance (ERI-S) [37] was translated only in Mandarin Chinese and tested amongst mainland Chinese healthcare workers [38] . The working culture and language 


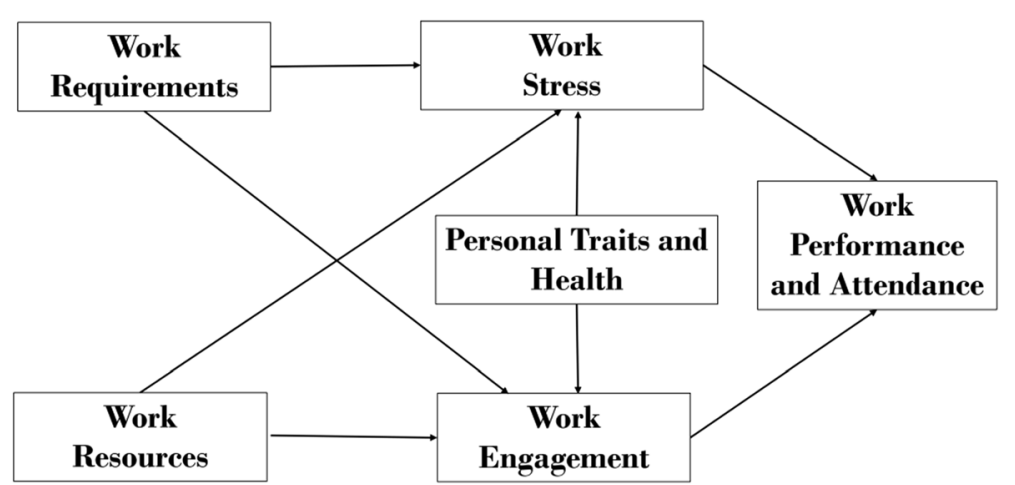

Fig. 1 Theoretical framework of presenteeism exposures on employee psychosocial emotions, work performance and attendance

\section{MPEPS-N VALIDATION PROCEDURE TIMELINE}

\section{QUESTIONNAIRE DEVELOPMENT}

- Systematic review to select previous validated scales

- Content validation by experts

- Translation/ Back translation

- Input from experts on translation accuracy

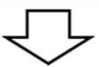

\section{VALIDITY AND RELIABILITY OF MPEPS-N AT H1} $(\mathrm{N}=295)$

- Distribution of preliminary 92-item survey

- CFA refinement procedure

- Test retest reliability (H1: $\mathbf{N}=\mathbf{8 0}$ )

- Internal consistency

- Convergent and discriminant validity<smiles>C1=CC2CCC=C1C2</smiles>

\section{VALIDITY AND RELIABILITY OF MPEPS-N AT H2} ( $N=1146)$

- Distribution of reduced 69-item survey

- CFA factor structure confirmation

- Internal consistency

- Convergent and discriminant validity 
Table 1 MPEPS-N domains, subdomains and sample items

\begin{tabular}{|c|c|c|c|c|c|}
\hline Domain & Subdomains & Sample items & Adopted Questionnaire & $\begin{array}{l}\text { Item \# } \\
\text { before } \\
\text { CFA }\end{array}$ & $\begin{array}{l}\text { Item } \\
\# \\
\text { after } \\
\text { CFA }\end{array}$ \\
\hline \multirow[t]{6}{*}{$\begin{array}{l}\text { Work } \\
\text { Resources }\end{array}$} & Task Significance ${ }^{a}$ & $\begin{array}{l}\text { The results of my work can significantly impact the lives of } \\
\text { patients under my care }\end{array}$ & $\begin{array}{l}\text { Work Design Questionnaire } \\
\text { (WDQ) }\end{array}$ & 4 & 4 \\
\hline & Work Schedule & $\begin{array}{l}\text { My job allows me to independently determine how to complete } \\
\text { my tasks. }\end{array}$ & & 3 & 2 \\
\hline & Social Support ${ }^{\mathrm{a}}$ & My job provides me the opportunity to develop close friendships. & & 6 & 5 \\
\hline & Social Feedback ${ }^{a}$ & $\begin{array}{l}\text { I receive feedback on my performance from other people in my } \\
\text { organization (such as manager and coworkers). }\end{array}$ & & 3 & 3 \\
\hline & Organizational Care ${ }^{a}$ & $\begin{array}{l}\text { The management of my organization are interested in the } \\
\text { health and well-being of the personnel. }\end{array}$ & $\begin{array}{l}\text { Nordic Psychological \& Social } \\
\text { Factors at Work (QPSNordic) }\end{array}$ & 3 & 2 \\
\hline & Rewards $^{a}$ & $\begin{array}{l}\text { Considering all my efforts and achievements, my job promotion } \\
\text { prospects are adequate. }\end{array}$ & Effort-reward imbalance (ERI-S) & 7 & 3 \\
\hline \multirow[t]{6}{*}{$\begin{array}{l}\text { Work } \\
\text { Demands }\end{array}$} & $\begin{array}{l}\text { Initiated } \\
\text { interdependence }^{a}\end{array}$ & Unless my job gets done, other jobs cannot be completed. & $W D Q$ & 3 & 0 \\
\hline & Physical demands ${ }^{a}$ & My job requires a great deal of muscular endurance. & & 3 & 3 \\
\hline & Effort $^{\mathrm{a}}$ & $\begin{array}{l}\text { I have constant time pressure due to a heavy work load. } \\
\text { Over the past few years, my job has become more and more } \\
\text { demanding. }\end{array}$ & Effort-reward imbalance (ERI-S) & 3 & 3 \\
\hline & $\begin{array}{l}\text { Team psychological } \\
\text { job demands }\end{array}$ & $\begin{array}{l}\text { Doctors do not care enough about patients. } \\
\text { There is conflict between doctors and nurses over therapy. }\end{array}$ & Herschbach 1992 & 4 & 4 \\
\hline & Work conditions $^{a}$ & $\begin{array}{l}\text { The wards/ rooms are cramped } \\
\text { I have/had muscle pain/discomfort in my body due to work }\end{array}$ & $\begin{array}{l}\text { Dutch Musculoskeletal } \\
\text { Questionnaire }\end{array}$ & 2 & 0 \\
\hline & Ease of Substitution ${ }^{a}$ & $\begin{array}{l}\text { I would rather go to work while unfit than to find a colleague } \\
\text { to substitute for me. } \\
\text { Being a healthcare worker professional, I would attend my } \\
\text { patients first even when I am unfit to go to work. }\end{array}$ & $\begin{array}{l}\text { (Arronson }+4 \text { Self Developed } \\
\text { Questions) }\end{array}$ & 6 & 3 \\
\hline Work Stress & $\begin{array}{l}\text { Depersonalization } \\
\text { and emotional } \\
\text { exhaustion }^{\text {b }}\end{array}$ & $\begin{array}{l}\text { Original items of Maslach Burnout Inventory English version } \\
\text { cannot be reproduced here due to copyright issues }\end{array}$ & $\begin{array}{l}\text { Maslach burnout Inventory } \\
\text { (MBI) }\end{array}$ & 14 & 8 \\
\hline $\begin{array}{l}\text { Work } \\
\text { Engagement }\end{array}$ & - & $\begin{array}{l}\text { At my job, I feel strong and vigorous. } \\
\text { I feel happy when I am working intensely. }\end{array}$ & $\begin{array}{l}\text { Utrecht work engagement } \\
\text { questionnaire (UWES) }\end{array}$ & 9 & 8 \\
\hline $\begin{array}{l}\text { Personal } \\
\text { Health and } \\
\text { Traits }\end{array}$ & $\begin{array}{l}\text { Health Locus of } \\
\text { Control }^{a}\end{array}$ & $\begin{array}{l}\text { If I get sick, it is my own behavior which determines how soon I } \\
\text { get well again. } \\
\text { If I take the right actions, I can stay healthy. }\end{array}$ & $\begin{array}{l}\text { Multidimensional Health locus } \\
\text { of control A (MHLC-A) }\end{array}$ & 6 & 5 \\
\hline \multirow[t]{2}{*}{$\begin{array}{l}\text { Work } \\
\text { Productivity }\end{array}$} & $\begin{array}{l}\text { Presenteeism } \\
\text { Frequency }^{\mathrm{C}}\end{array}$ & $\begin{array}{l}\text { How many times during the last year have you gone to work } \\
\text { when you should have been on sick leave due to your health } \\
\text { condition? }\end{array}$ & Aronsson 2000 & 1 & \\
\hline & Productivity ${ }^{d}$ & $\begin{array}{l}\text { Using the same 0-to-10 scale, how would you rate your overall } \\
\text { job performance on the days you worked during the past } 4 \\
\text { weeks ( } 28 \text { days)? }\end{array}$ & $\begin{array}{l}\text { WHO-health and performance } \\
\text { questionnaire (WHO-HPQ) }\end{array}$ & 7 & \\
\hline $\begin{array}{l}\text { Additional } \\
\text { Items }\end{array}$ & $\begin{array}{l}\text { Quality of life } \\
\text { General health }\end{array}$ & $\begin{array}{l}\text { How would you rate your quality of life? } \\
\text { Compared with people of your age, do you consider that your } \\
\text { health condition as. }\end{array}$ & $\begin{array}{l}\text { WHO- Quality of Life } \\
\text { (WHO-QOL BREF) }\end{array}$ & 2 & \\
\hline Demographics & & $\begin{array}{l}\text { Please indicate highest degree of nursing training. } \\
\text { Please indicate the department that you spend the most of your } \\
\text { time in. }\end{array}$ & $\begin{array}{l}\text { Thematic household survey } \\
\text { (THS) and healthcare } \\
\text { manpower survey (HMS) }\end{array}$ & 6 & \\
\hline
\end{tabular}

\footnotetext{
${ }^{\mathrm{a}} 5$-point Likert scale (1- strongly disagree to 5- strongly agree)

b7-point Likert scale ( 0 - never to 6 - every day)

c4-point Likert scale (1 - never, 2 - once, 3-2 to 5 times, 4 -> 5 times)

${ }^{\mathrm{d} V i s u a l}$ analogue scale (0- worst performance to 10 - top performance)

${ }^{\text {e}} 5$-point Likert scale (1- very poor to 5 - very good)
}

(Cantonese Chinese) is distinctly different from our sample of Hong Kong nurses. Maslach burnout Inventory (MBI) [39] was validated and widely used in Hong Kong education sector but not healthcare sector [40], while only the English version was used in a Hong Kong nursing student burnout survey [41]. Utrecht work 
engagement questionnaire (UWES) has a Cantonese translation but has been tested amongst elderly workers only [42], in which the respondent characteristics are distinctly different from our sample (acute hospital nurses). Multidimensional Health locus of control (MHLC) form C but not Form A has a validated Cantonese Chinese version, Form $\mathrm{C}$ is for responders with existing health condition (e.g. patients), while Form A and B measures "general" health locus of control [43, 44]. Thus, a cross-cultural questionnaire validation study is necessary to establish the validity and reliability of these scales for Hong Kong nurse presenteeism and exposures.

The preliminary questionnaire domains, subdomains, sources, number of items and a sample item from each scale are listed in Table 1 (full version of scale is available upon request). As per the hypothesized model, the preliminary questionnaire consisted of five domains (and subdomains): work resources, work demands, work stress, work engagement, personal traits and health. The attitudinal, perceptual, and personal traits items used either a 5-point Likert scale (1- strongly disagree to 5 strongly agree) or a 7 -point scale $(0$ - never to 6 - every day) [45].

The work productivity items were adapted from the previously validated World Health Organization Health and Work Performance Questionnaire (WHO-HPQ) short form [46]. Items included self-reported number of hours worked in the past 7 days, number of days missed work in the past 28 days, and number of expected working hours per week; and self-assessed job performance 1) compared with others, 2) last year and 3) during past 28 days on a 10 -point Likert scale (0- worst performance, 10- top performance). An additional item on selfassessed sickness presenteeism frequency on a 4-point Likert scale ( 1 - never, 2 - once, 3-2 to 5 times, 4 - > 5 times) was added [2]. Overall quality of life and general health status (two items) adopted from WHOQOLBREF were also included. The pre-expert content validated questionnaire also contained six individual co-variates (age, sex, staff grade/rank, education, work schedule (shift/regular hours), department) with 110 items in total.

\section{Content validation}

A panel of seven international and local experts comprising specialists in psychometrics, nursing research, nursing administration and health economics, policy and management assessed the preliminary items for face and content validity and provided structured comments on relevance and comprehensibility.

Using a content validation index (CVI) each expert assessed the per-item face and content validity on a 4point scale (1- not relevant, 2- somewhat relevant, 3- quite relevant and 4- highly relevant). Items with an average score lower than 0.8 were discarded [47], leaving 92 items in the preliminary questionnaire after expert content validation.

\section{Translation}

The questionnaire was back-translated (English-Cantonese Chinese-English) and the translation was then confirmed by international and local Cantonese-Chinese speaking nurses, nurse managers and psychometrics experts and moderated by an 'editor-in-chief' to achieve consensus.

\section{Questionnaire sample}

Two acute hospitals in Hong Kong with distinct organizational structures, hospital size, patient characteristics, religious affiliation, and management style were selected to test the applicability of questionnaire in different hospital environments. All full-time nurses working in the two hospitals (Preliminary questionnaire at Hospital 1: $N=295$ and reduced main round questionnaire at Hospital 2: $N=1146$ ) were invited to participate in the validation study. The selected sample size was adequate as a sample size of ten cases per item is recommended for each CFA analysis [48]. Part-time and outsourced nurses were excluded as they have different work patterns and thus organizational stressors than full-time nurses [49].

A random sample of 80 nurses from Hospital 1 were selected for test-retest reliability 4 weeks post the initial survey. The test-retest reliability sample size was determined using $\mathrm{R}$ software package "pwr", assuming an alpha of 0.05 , power of 0.8 to detect a medium effect size of 0.4 and an estimated dropout rate of $60 \%$.

\section{Model fitness and refinement}

Confirmatory factor analysis (CFA) using maximum likelihood (ML) estimation and pairwise deletion of missing values was used to establish scale factor structures [50]. CFA reduction for each presenteeism exposure domain was first carried out in $\mathrm{H} 1$ sample, whereas a second round of CFA on the reduced domains were carried out in $\mathrm{H} 2$ to confirm the factor structures in different hospital environments (Fig. 2). In each CFA model, items were loaded onto respective subdomains: work resources (6-factor), work demands (6-factor), work stress (2-factor), work engagement (1-factor), health locus of control (1-factor).

Although CFA could not be carried out on a single item (presenteeism) or numerical responses (productivity), self-reported sick leave at $\mathrm{H} 1$ was compared with administrative payroll records on the number of sick leaves taken and there was strong correlation (0.93). This method was also used for validation of the WHO- 
HPQ Persian version in Iranian healthcare workers with comparable correlation between self-reported data and administrative data [51].

To improve model fitness, items with factor loading < 0.4 and standardized residual covariance $>1.96$ or $<-$ $1.96(p<0.05)$ were deleted. Between error variance paths were added if modification indices (MI) were more than six and were supported by theory or prior research [52].

\section{Fit indices}

Model fit was evaluated with chi-squared test ( $\mathrm{x} 2 / \mathrm{df})$, and root mean square error of approximation (RMSEA). Relative fit including comparative fit index (CFI), Tucker Lewis index (TLI), Goodness-of-fit index (GFI) and standardized root-mean-square residual (SRMR) were also used. Values of 1) X2/df ratio <3.0, 2) CFI, TLI and GFI > $0.95,3)$ SRMR and RMSEA $<0.08$ were used to assess model fit [53].

\section{Questionnaire validity and reliability Test-retest reliability}

Intra-class correlation coefficient (ICC) 2-way random measurement was used to determine test-retest reliability of the five domains; where ICC values between 0.4 and 0.74 , and values greater than 0.75 indicate moderate and excellent reliability respectively [54].

\section{Internal consistency}

Cronbach's alpha coefficient was used to assess internal consistency of the domains and subdomains, where alpha values above 0.7 were considered satisfactory [48].

\section{Convergent and discriminant validity}

Pearson correlation coefficients were used to assess convergent and discriminant validity between domain and subdomain mean scores. Convergent validity was hypothesized to be supported if both pairs of mean domain scores of 1) work resources and work engagement, and 2) the work demands, and work stress are positively correlated. Divergent validity was hypothesized to be supported if the work stress and work engagement mean domain scores are inversely correlated. Health locus of control domain was predicted to be negatively correlated to work stress but positively correlated to work engagement domain.

Presenteeism was hypothesized to be positively associated with work demands and work stress, while negatively associated with work resources, health locus of control, work engagement, quality of life, general health; and vice versa for the hypothesized association between the domains with productivity.

For convergent and divergent validity assessment thresholds, Pearson correlation coefficients of $<0.49$,
$0.50-0.74$ and $>0.75$ indicates weak, moderate and strong relationship respectively [54]. For discriminant validity assessment, inter-domain Pearson correlation coefficients are hypothesized to be lower than intra-domain coefficients.

Confirmatory factor analysis (CFA) was performed in $\mathrm{R}$ (version 3.4.1) using the "lavaan" package (version 0.5-23.1097). Cronbach's alpha, ICC values and Pearson correlation coefficients were calculated using SPSS version 24.

\section{Ethics approval}

Ethics approval was obtained from the Institutional Review Board of the University of Hong Kong/Hospital Authority Hong Kong West Cluster (HKU/HA HKW IRB) (reference number: UW 16-102) and Hospital Authority Kowloon West Cluster Research Ethics Committee (reference number: KW/EX-17-028(108-07)).

\section{Results}

Response rate (RR)

The preliminary 92-item questionnaire was completed by 246 of 295 nurses in $\mathrm{H} 1\left(\mathrm{RR}_{\text {Hospital } 1}=83 \%\right)$ and main round CFA reduced 69-item questionnaire was completed by 824 of 1146 nurses in $\mathrm{H} 2\left(\mathrm{RR}_{\text {Hospital } 2}=71.9 \%\right)$. The nurses in Hospital 1 vs Hospital 2 were significantly older, fewer had tertiary level education, were more likely to work day-time shift and fewer were in middle management grades (Table 2). Completed 4-week testretest questionnaires were returned by 50 out of the 80 $(\mathrm{RR}=62.5 \%)$ randomly selected nurses at Hospital 1.

\section{Confirmatory factor analysis}

Confirmatory Factor Analysis for each of Hospital 1 and Hospital 2 domains were independently tested. After carrying out model refinement procedures by deleting items with loadings $<0.4$ and standardized residual covariances $>1.96$ or $<-1.96$ (number of deleted items per subdomain listed in Table 1), satisfactory fit indices were demonstrated for both Hospital 1 and Hospital 2 with values greater than 0.95 (for CFI and TLI) [55]. However fit indices for work engagement $(\mathrm{CFI}=0.939$, TLI $=$ 0.899 ) and health locus of control (TLI $=0.939)$ in Hospital 2 were weaker. The items for the subdomains work conditions and initial independence failed to load on their respective latent constructs, thus the two subdomains were deleted from work demands domain for the CFA analysis. RMSEA for all scales were below 0.08 , SRMR values below 0.06 , indicating acceptable model fit.

\section{Internal consistency}

Despite differences in some of the domains and subdomains mean scores between Hospitals 1 and 2, Cronbach alpha for all domains (work resources, work demands, 
Table 2 A comparison of demographic and work-related characteristics for nurses in Hospital 1 and 2

\begin{tabular}{|c|c|c|c|}
\hline Characteristics & $\begin{array}{l}\text { Preliminary questionnaire Hospital } 1(n=246) \\
\mathrm{n}(\%)\end{array}$ & $\begin{array}{l}\text { Main round Questionnaire Hospital } 2(n=824) \\
\mathrm{n}(\%)\end{array}$ & $P$-value \\
\hline \multicolumn{4}{|l|}{ Gender } \\
\hline Male & $25(10.2)$ & $95(11.5)$ & \multirow[t]{2}{*}{0.63} \\
\hline Female & $221(89.8)$ & $729(88.5)$ & \\
\hline \multicolumn{4}{|l|}{ Age Group } \\
\hline$\leq 30$ & $38(19.9)$ & $226(28.4)$ & \multirow[t]{4}{*}{$<0.001^{* *}$} \\
\hline $31-40$ & $55(28.8)$ & $196(24.6)$ & \\
\hline $41-50$ & $48(25.1)$ & $263(33.0)$ & \\
\hline$\geq 51$ & $50(26.2)$ & $111(14.0)$ & \\
\hline \multicolumn{4}{|l|}{ Education } \\
\hline Certificate/ Diploma & $59(28.0)$ & $72(9.1)$ & \multirow[t]{4}{*}{$<0.001^{* *}$} \\
\hline Associate Diploma/ Higher Diploma & $43(20.5)$ & $47(6.0)$ & \\
\hline Bachelor's Degree (BscN/BN) & $65(31.0)$ & $432(54.8)$ & \\
\hline Postgraduate Degree & $43(20.5)$ & $237(30.1)$ & \\
\hline \multicolumn{4}{|l|}{ Nurse Ranking } \\
\hline Junior staff (EN/RN) $)^{a}$ & $198(80.5)$ & $618(75.0)$ & \multirow[t]{3}{*}{$<0.001^{* *}$} \\
\hline Middle management (APN/NC) & $31(12.6)$ & $171(20.8)$ & \\
\hline Senior management (WM/UM/DOM) & $17(6.9)$ & $35(4.2)$ & \\
\hline \multicolumn{4}{|l|}{ Working Schedule } \\
\hline Shift schedule & $164(69.5)$ & $664(82.8)$ & \multirow[t]{2}{*}{$<0.001^{* *}$} \\
\hline Regular schedule (9 am-6 pm) & $72(30.5)$ & $138(17.2)$ & \\
\hline \multicolumn{4}{|l|}{ Department } \\
\hline A\&E and Outpatients ${ }^{\mathrm{b}}$ & $14(5.9)$ & $94(12.0)$ & \multirow[t]{4}{*}{$0.04^{*}$} \\
\hline Medicine $^{c}$ & $105(44.3)$ & 309 (39.6) & \\
\hline Surgery ${ }^{d}$ & $90(38.0)$ & $303(38.8)$ & \\
\hline Others $^{\mathrm{e}}$ & $28(11.8)$ & $75(9.6)$ & \\
\hline
\end{tabular}

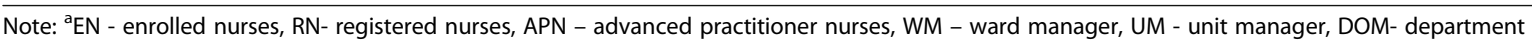
operations manager

${ }^{\mathrm{b}} \mathrm{A} \& \mathrm{E}$ and outpatients - includes accident and emergency, ambulatory Care and outpatients

${ }^{\mathrm{C}}$ Medicine - includes medicine, geriatrics, pediatrics and intensive care unit (ICU)

${ }^{\mathrm{d} S u r g e r y}$ - includes surgery, obstetrics, gynecology and operation theatre

ethers - includes administration, management, residential care, public health, rehabilitation, occupational Health, community nursing, mental health, psychiatry, addiction treatment and others

${ }^{*} p<0.05 ;{ }^{* *} p<0.001$

work stress, work engagement and health locus of control) and subdomains (task significance, work schedule, social support, social feedback, organizational care, rewards, physical demands, team psych demands, effort, ease of substitution, emotional exhaustion and depersonalization) were satisfactory (domains range: 0.75 to 0.90 ; subdomains range: 0.65 to 0.96 ), except for ease of substitution $(\alpha=0.65)$ (Table 3).

\section{Convergent and discriminant validity}

Inter-domain mean scores were more positively correlated to each other as compared to intra-domain subdomain mean scores, thereby satisfying the convergent/ discriminant validity criteria (Additional file 1: Tables S1a and S1b).
Although the 'ease of substitution' subdomain mean score both positively correlated with "work engagement" $(r=0.30, p<0.01)$ and "work demands" $(r=0.54, p<$ 0.01 ) in Hospital 1, 'ease of substitution' satisfied the convergent and discriminant validity criteria in Hospital 2. Health locus of control (HLOC) was positively correlated with the work demands domain in Hospital $1(r=$ $0.20, p<0.01$ ) but not in Hospital 2.

Hospital 2 data showed significant associations between sickness presenteeism frequency and all psychosocial work domains as hypothesized (Table 4). Fewer work psychosocial domains were significantly associated with the presenteeism measures in Hospital 1 as compared to Hospital 2. Presenteeism and productivity were significantly associated with all work resources, work 
Table 3 Means, standard deviations and Cronbach's alpha coefficient for questionnaire domains and subdomains in Hospitals 1 and 2

\begin{tabular}{|c|c|c|c|c|c|}
\hline & \multirow{2}{*}{$\begin{array}{l}\text { Hospital } 1 \\
\text { Alpha }\end{array}$} & \multicolumn{3}{|l|}{ Hospital 2} & \multirow[b]{2}{*}{$P$-value } \\
\hline & & Mean (SD) & Alpha & $\overline{\text { Mean }(\mathrm{SD})}$ & \\
\hline Work Resources & 0.90 & $3.32(0.54)$ & 0.90 & $3.36(0.52)$ & 0.40 \\
\hline Task Significance ${ }^{a}$ & 0.90 & $3.73(0.74)$ & 0.86 & $3.75(0.68)$ & 0.19 \\
\hline Work Schedule ${ }^{a}$ & 0.90 & $3.28(0.90)$ & 0.87 & $3.34(0.87)$ & 0.29 \\
\hline Social Support ${ }^{a}$ & 0.77 & $3.24(0.69)$ & 0.76 & $3.36(0.63)$ & $<0.001^{* *}$ \\
\hline Social Feedback ${ }^{a}$ & 0.87 & $3.39(0.75)$ & 0.89 & $3.33(0.73)$ & 0.24 \\
\hline Organizational Care ${ }^{a}$ & 0.94 & $2.61(0.90)$ & 0.91 & $2.65(0.96)$ & 0.57 \\
\hline Rewards $^{a}$ & 0.75 & $3.02(0.74)$ & 0.81 & $3.16(0.77)$ & $0.01^{*}$ \\
\hline Work Demands & 0.78 & $3.23(0.44)$ & 0.78 & $3.38(0.39)$ & $<0.001^{* *}$ \\
\hline Physical Demands ${ }^{a}$ & 0.96 & $3.53(1.05)$ & 0.93 & $3.89(0.83)$ & $<0.001^{* *}$ \\
\hline Team Psych Demands ${ }^{a}$ & 0.85 & $2.76(0.73)$ & 0.82 & $2.96(0.71)$ & $<0.001^{* *}$ \\
\hline Effort $^{a}$ & 0.82 & $4.01(0.77)$ & 0.80 & $3.96(0.72)$ & 0.36 \\
\hline Ease of Substitution ${ }^{a}$ & 0.65 & $2.99(0.92)$ & 0.69 & $3.10(0.89)$ & 0.09 \\
\hline Work Engagement ${ }^{\mathrm{a}}$ & 0.87 & $3.03(0.74)$ & 0.90 & $3.09(0.71)$ & 0.27 \\
\hline Health Locus of Control ${ }^{a}$ & 0.75 & $3.13(0.58)$ & 0.76 & $2.91(0.69)$ & 0.06 \\
\hline Work Stress & 0.88 & $2.56(1.31)$ & 0.89 & $2.05(1.31)$ & $<0.001^{* *}$ \\
\hline Emotional Exhaustion ${ }^{b}$ & 0.92 & $3.24(1.57)$ & 0.92 & $2.66(1.59)$ & $<0.001^{* *}$ \\
\hline Depersonalization ${ }^{\mathrm{b}}$ & 0.84 & $1.42(1.46)$ & 0.90 & $1.03(1.38)$ & $<0.001^{* * *}$ \\
\hline
\end{tabular}

Note: ${ }^{\text {a }} 5$-point Likert scale (1- strongly disagree to 5 - strongly agree)

${ }^{b} 7$-point Likert scale (0 - never to 6 - every day)

${ }^{*} p<0.05 ;{ }^{* *} p<0.001$

Table 4 Correlations between presenteeism productivity and frequency with work psychosocial domains and subdomains in Hospitals 1 and 2

\begin{tabular}{|c|c|c|c|c|}
\hline & \multicolumn{2}{|l|}{ Hospital 1} & \multicolumn{2}{|l|}{ Hospital 2} \\
\hline & Presenteeism & Productivity & Presenteeism & Productivity \\
\hline Work Resources & 0.00 & $0.25^{* *}$ & $-0.24^{* *}$ & $0.21^{* *}$ \\
\hline Task Significance & 0.10 & $0.13^{*}$ & $-0.08^{*}$ & $0.22^{* *}$ \\
\hline Work Schedule & -0.02 & $0.21^{* *}$ & $-0.20^{* *}$ & $0.10^{* *}$ \\
\hline Social Support & 0.04 & $0.28^{* *}$ & $-0.12^{* *}$ & $0.17^{* *}$ \\
\hline Feedback & 0.04 & $0.22^{* *}$ & $-0.16^{* *}$ & $0.18^{* *}$ \\
\hline Organizational Care & -0.12 & 0.08 & $-0.26^{* *}$ & $0.12^{* *}$ \\
\hline Rewards & 0.02 & 0.11 & $-0.23^{* *}$ & $0.21^{* *}$ \\
\hline Work Demands & $0.28^{* *}$ & $0.21^{* *}$ & $0.22^{* *}$ & 0.01 \\
\hline Physical Demands & 0.11 & 0.08 & $0.16^{* *}$ & -0.06 \\
\hline Team Psych Demands & 0.08 & 0.11 & $0.14^{* *}$ & $-0.07^{*}$ \\
\hline Effort & $0.27^{* *}$ & $0.16^{*}$ & $0.23^{* *}$ & -0.03 \\
\hline Ease of Substitution & $0.23^{* *}$ & 0.09 & $0.23^{* *}$ & -0.04 \\
\hline Work Engagement & 0.03 & $0.29^{* *}$ & $-0.12^{* *}$ & $0.34^{* *}$ \\
\hline Health Locus of Control & -0.01 & $0.13^{*}$ & $-0.13^{* *}$ & 0.06 \\
\hline Work Stress & $0.19^{* *}$ & -0.12 & $0.21^{* *}$ & $-0.30^{* *}$ \\
\hline Depersonalization & 0.10 & $-0.17^{* *}$ & $0.08^{*}$ & $-0.29^{* *}$ \\
\hline Emotional Exhaustion & $0.22^{* *}$ & -0.03 & $0.27^{* *}$ & $-0.23^{* *}$ \\
\hline Quality of Life & $-0.18^{* *}$ & $0.27^{* *}$ & $-0.20^{* *}$ & $0.29^{* *}$ \\
\hline General Health & $-0.21^{* *}$ & $0.27^{* *}$ & $-0.31^{* *}$ & $0.23^{* *}$ \\
\hline
\end{tabular}

${ }^{*} p<0.05 ;{ }^{* *} p<0.001$ 
engagement and work stress constructs in Hospital 2. Although presenteeism significantly correlated with all work demands domains and subdomains, productivity only significantly correlated with team psychological demands within the work demands construct. Health locus of control was significantly negatively associated with productivity but not presenteeism in Hospital 2.

\section{Test-retest reliability}

The Hospital 1 4-week test-retest ICC domain scores achieved moderate reliability (0.4-0.7), ranging from 0.42 (95\% CI: $0.16-0.64$ ) for work stress domain to 0.71 (95\% CI: 0.54-0.82) for work resources domain (Table 5). The nurse demographics and characteristics did not differ significantly between those who responded in the test and retest surveys.

\section{Discussion}

As presented in this paper, a reliable presenteeism exposure and productivity questionnaire is developed and validated amongst nurses working in two hospitals. These hospitals have different working environments vis organizational structure, work place demands, patient characteristics, management styles, hospital size and culture. To our knowledge, this scale is the first to measure the association between presenteeism productivity and organizational factors, work place exposures and personal characteristics in nurses working in a densely populated Asian city and serving a rapidly aging post-war baby boomer population.

Although the internal consistency of the 'ease of substitution' subdomain (Hospital 1: $\alpha=0.65$, Hospital 2; $\alpha=0.69$ ) is moderate ( $\alpha$ is acceptable at 0.5 and above) as recommended by Nunnally [48], there is strong empirical evidence in this field that the 'ease of substitution' subdomain captures a crucial construct that contributes to presenteeism behaviour, therefore a decision was made to retain this subdomain in the instrument $[2,9$, 24, 56-58].

The items within the 'work conditions' and 'initial independence' subdomains failed to load onto the construct as hypothesized, perhaps due to the differences in cultural and work autonomy in the East vs the West. The overall convergent and divergent validity were satisfactory except for the 'ease of substitution' subdomain. Attitudes towards 'ease of substitution' among nurses working in an East vs West setting may reflect cultural differences related to flexible work schedules and work life balance. Nurse managers in Korea and Japan, though acknowledging the association between work schedule flexibility, job satisfaction and turnover rate, face a dilemma managing the perceived inequity among staff when accommodating request for flexible working schedules assignments [59, 60]. This contrasts with outcomes of a multi-country European study of RNs working in units with higher scheduling flexibility having lower intention to leave [61]. This study indicates the importance of cross-cultural validation as distinct population samples may comprehend or perceive given constructs differently. In this case, a potential evidencebased human resources strategic target (increasing work autonomy and flexibility of working schedule) may be effective in European but not Asian nurses. Researchers are also encouraged to validate the MPEPS scale and test its applicability in other cultural and occupational settings in the future.

Confirmatory factor analysis of the refined survey domains demonstrated satisfactory model fit. The chisquare test result differences as noted between the two hospitals were likely due the differences between sample size, the hospital operational environments (long term care vs district level acute care) and organizational culture particularly of that within the nursing structures.

The inconsistent finding between Hospital 1 vs Hospital 2 in the relationship between WHO-HPQ scale presenteeism score and work psychosocial domains may be explained by a lack of statistical power to detect a difference in Hospital 1 and suggests the need for further work in this area.

Convergent and discriminant validity was found for sickness presenteeism and presenteeism score (WHOHPQ scale) for all exposures except health locus of

Table 5 Four-week Test-retest mean scores and intra-class correlation coefficients for the preliminary questionnaire at Hospital 1 $(N=50)$

\begin{tabular}{llll}
\hline Domains & Test & Retest & \\
& Mean (SD) & Mean (SD) & ICC $(95 \%$ Cl) \\
\hline Work Demands $^{\text {a }}$ & $3.34(0.48)$ & $3.22(0.59)$ & $0.58(0.37-0.74)$ \\
Work Resources $^{\text {a }}$ & $3.33(0.57)$ & $3.36(0.56)$ & $0.71(0.54-0.82)$ \\
Work Stress $^{b}$ & $2.95(1.19)$ & $2.92(0.81)$ & $0.42(0.16-0.64)$ \\
Work Engagement $^{\text {a }}$ & $3.26(0.68)$ & $3.29(0.58)$ & $0.70(0.52-0.82)$ \\
Personal Health locus of control $^{\text {a }}$ & $3.04(0.66)$ & $3.03(0.64)$ & $0.53(0.30-0.70)$ \\
\hline
\end{tabular}

${ }^{\mathrm{a}} 5$-point Likert scale (1- strongly disagree to 5- strongly agree)

b7-point Likert scale ( 0 - never to 6 - every day)

${ }^{\mathrm{c}} 0.4<\mathrm{ICC}<0.7$ confirms that moderate reliability is achieved 
control and work demands for Hospital 2 indicating work demands although having an impact on sickness presenteeism frequency, may not play a role in on the job productivity.

Researchers can utilize the validated MPEPS-N and extend existing presenteeism research on employee health-related presenteeism medical and productivity cost burden to evidence-based identification of modifiable cultural and occupational specific human resources intervention targets [1]. Moreover, as few existing studies have established causal relationship between presenteeism and its risk factors [20], researchers are encouraged to adopt MPEPS-N in prospective studies in the future. With the validation of this standardized multi-dimensional presenteeism exposures measure, improvements in the quality, comprehensiveness and generalizability of findings of current nurse presenteeism and exposures research are anticipated with the adoption of MPEPS-N [20].

\section{Limitations}

Data-driven refinements to the hypothesized model and subsequent validated questionnaire are only considered preliminary and representative of Hong Kong public hospital nurses. To further improve the generalizability of this measure, further work must be tested amongst other healthcare professionals. The data used for the validation were collected at two times points 1 year apart, from two distinct hospitals, in two different operational modes: hospital utilization was very high and the nurses were under pressure (during the winter flu surge period) and the second when hospital utilization was considered normal and nurses under less pressure. However, the outcomes demonstrate the stability of the factor structure and the underlying constructs being measured.

The limitations of self-reported questionnaire apply to the MPEPS-N survey, such as social desirability bias (providing socially acceptable answers) and acquiescent response bias (unified response to all questions with "yes"). To reduce social desirability bias, confidentiality and anonymity of responses were assured by taking the following precautions: 1) each survey was labelled with unique identification number (UIN) for test-retest assessment to avoid individual identification during data analysis, 2) self-sealed return envelope was provided, and 3) researchers collected the completed questionnaires at each ward to ensure that hospital management or supervisors did not have access to individual level data responses. Acquiescent response bias was tested by intercalating the order of opposite domain items in the survey. The satisfactory convergent and divergent validity between the domains and subdomains eliminated the possibility of acquiescent response bias for our collected data.

\section{Conclusion}

The MPEPS- $\mathrm{N}$ is systematically validated in this paper for use in an Asian healthcare organization setting. As with other research, the study has demonstrated the potential workplace impact or moderating effect of the hypothesized domains on nursing staff. The outcome, which focuses on an organizational and well-being approach is supported by the theoretical work of others. Such a validated instrument will give nurse managers in Asia better information to consider the relationships between the attributes of work demands and work resources, work stress and work engagement when making staff work allocation and job demand decisions. Further research is needed to demonstrate the potential work-related, organizational and personal factors in Asian health care settings that are postulated to impact presenteeism.

\section{Additional file}

Additional file 1: Table S1a. Hospital 1 Correlation matrix between the 5-factor domains and internal consistency, Table S1b. Hospital 2 Correlation matrix between the 5-factor domains and internal consistency. (DOCX $54 \mathrm{~kb}$ )

\section{Abbreviations}

A\&E: Accident and emergency; APN: Advanced practitioner nurses; CFA: Confirmatory factor analysis; CFI: Comparative fit index; CVI: Content validation index; DOM: Department operations manager; EN: Enrolled nurses; ERI-S: Effort reward imbalance scale; GFI: Goodness-of-fit index; ICC: Intraclass correlation coefficient; ICU: Intensive care unit; JD-R: Job-Demands Resources Model; MHLC: Multidimensional Health locus of control; ML: Maximum likelihood; MPEPS-N: Multidimensional Presenteeism Exposures and Productivity Survey (Nurses); QPS Nordic: Nordic Psychological \& Social Factors at Work; RMSEA: Root mean square error of approximation; RN: Registered nurses; RR: Response rate; SRMR: Standardized root-meansquare residual; TLI: Tucker-Lewis index; UM: Unit manager; UWES: Utrecht work engagement scale; WDQ: Work design questionnaire; WHO-HPQ: World Health Organization Health and Work Performance Questionnaire; WHOQOLBREF: World Health Organization Quality of Life Instrument, Short Form; WM: Ward manager

\section{Acknowledgements}

The authors would like the following international experts and nurse managers in contributing to our questionnaire validation and translation process: Mr. Anders Yuen, Ms. Viola Lee, Dr. Sarah Kagan, Dr. Helen Teng, Dr. Julia Tang, Ms. Cynthia Yau, Dr. Coco Chen. We would also like to thank all department operation managers, ward managers and frontline nursing staff for their participation and encouragement despite their heavy workload.

\section{Authors' contributions}

Study design, data analysis and interpretation: JJ and JL; statistical analysis: $J L$; supervision and mentorship: JJ. The manuscript was prepared and approved by all authors.

\section{Funding}

The author(s) received no specific funding for this work.

\section{Availability of data and materials}

The data and questionnaire that support the findings of this study are available on reasonable request from the corresponding author.

Ethics approval and consent to participate

Ethics approval was obtained from the Institutional Review Board of the University of Hong Kong/Hospital Authority Hong Kong West Cluster (HKU/ 
HA HKW IRB) (reference number: UW 16-102) and Hospital Authority Kowloon West Cluster Research Ethics Committee (reference number: KW/ EX-17-028(108-07)).

The information sheet states the purpose and nature of the study, potential benefits and risks of participating in the study, and that individual information collected will be kept anonymous and strictly confidential. Participants may decide whether or not to participate and they may withdraw anytime with no negative consequences. Consent to participate was obtained by participants sending back a completed survey.

\section{Consent for publication}

Not applicable.

\section{Competing interests}

The authors declare that they have no competing interests.

Received: 21 January 2019 Accepted: 25 July 2019

Published online: 02 August 2019

\section{References}

1. Schultz AB, Chen C-Y, Edington DW. The cost and impact of health conditions on presenteeism to employers. Pharmacoeconomics. 2009;27(5): 365-78.

2. Aronsson G, Gustafsson K. Sickness presenteeism: prevalence, attendancepressure factors, and an outline of a model for research. J Occup Environ Med. 2005;47(9):958-66.

3. Goetzel RZ, Guindon AM, Turshen IJ, Ozminkowski RJ. Health and productivity management: establishing key performance measures, benchmarks, and best practices. J Occup Environ Med. 2001;43(1):10-7.

4. Goetzel RZ, Hawkins K, Ozminkowski RJ, Wang S. The health and productivity cost burden of the "top 10" physical and mental health conditions affecting six large US employers in 1999. J Occup Environ Med. 2003;45(1):5-14.

5. Munro L. Absenteeism and presenteeism: possible causes and solutions: peer reviewed original article. South African Radiographer. 2007;45(1):21-3.

6. Hemp P. Presenteeism: at work-but out of it. Harv Bus Rev. 2004;82(10): 49-58.

7. Rainbow JG, Steege LM. Presenteeism in nursing: an evolutionary concept analysis. Nurs Outlook. 2017;65(5):615-23.

8. Bhatti KK, Qureshi TM. Impact of employee participation on job satisfaction, employee commitment and employee productivity. Int Rev Bus Res Papers. 2007;3(2):54-68

9. Aronsson G, Gustafsson K, Dallner M. Sick but yet at work. An empirical study of sickness presenteeism. J Epidemiol Community Health. 2000;54(7): 502-9.

10. Letvak SA, Ruhm CJ, Gupta SN. Nurses' presenteeism and its effects on selfreported quality of care and costs. Am J Nurs. 2012;112(2):30-8.

11. Widera E, Chang A, Chen HL. Presenteeism: a public health hazard. J Gen Intern Med. 2010;25(11):1244-7.

12. Institute of Medicine - Committee on the Robert Wood Johnson Foundation Initiative on the Future of Nursing. The future of nursing: Leading change, advancing health. Washington, DC: National Academies Press; 2011. Report No.: 0309158192

13. Demerouti $E$, Le Blanc PM, Bakker AB, Schaufeli WB, Hox J. Present but sick: a three-wave study on job demands, presenteeism and burnout. Career Dev Int. 2009;14(1):50-68.

14. Warren CL, White-Means SI, Wicks MN, Chang CF, Gourley D, Rice M. Cost burden of the presenteeism health outcome: diverse workforce of nurses and pharmacists. J Occup Environ Med. 2011;53(1):90-9.

15. Rantanen I, Tuominen R. Relative magnitude of presenteeism and absenteeism and work-related factors affecting them among health care professionals. Int Arch Occup Environ Health. 2011;84(2):225-30.

16. Kessler RC, Barber C, Beck A, Berglund P, Cleary PD, McKenas D, et al. The world health organization health and work performance questionnaire (HPQ). J Occup Environ Med. 2003;45(2):156-74.

17. Koopman C, Pelletier KR, Murray JF, Sharda CE, Berger ML, Turpin RS, et al. Stanford presenteeism scale: health status and employee productivity. J Occup Environ Med. 2002;44(1):14-20.

18. Lerner D, Amick BC III, Rogers WH, Malspeis S, Bungay K, Cynn D. The work limitations questionnaire. Med Care. 2001:72-85.
19. Goetzel RZ, Long SR, Ozminkowski RJ, Hawkins K, Shaohung W, Lynch W. Health, absence, disability, and Presenteeism cost estimates of certain physical and mental health conditions Affecting U.S. employers. J Occup Environ Med. 2004:46(4):398-412.

20. Lui JNM, Andres EB, Johnston JM. Presenteeism exposures and outcomes amongst hospital doctors and nurses: a systematic review. BMC Health Serv Res. 2018;18(1):985.

21. Dellve L, Hadzibajramovic E, Ahlborg G Jr. Work attendance among healthcare workers: prevalence, incentives, and long-term consequences for health and performance. J Adv Nurs. 2011;67(9):1918-29.

22. Gustafsson Senden M, Lovseth LT, Schenck-Gustafsson K, Fridner A. What makes physicians go to work while sick: a comparative study of sickness presenteeism in four European countries (HOUPE). Swiss Med Wkly. 2013;143:w13840.

23. Bakker AB, Demerouti $E$. The job demands-resources model: state of the art. J Manag Psychol. 2007;22(3):309-28.

24. Johns G. Attendance dynamics at work: the antecedents and correlates of presenteeism, absenteeism, and productivity loss. J Occup Health Psychol. 2011;16(4):483.

25. Nyberg A, Westerlund H, Magnusson Hanson LL, Theorell T. Managerial leadership is associated with self-reported sickness absence and sickness presenteeism among Swedish men and women. Scand J Soc Med. 2008; 36(8):803-11.

26. Kim M, Choi HO, Ryu E. Predictors of clinical nurses' presenteeism. Kor J Occup Health Nur. 2014;23(3):134-45.

27. See KC, Zhao MY, Nakataki E, Chittawatanarat K, Fang W-F, Faruq MO, et al. Professional burnout among physicians and nurses in Asian intensive care units: a multinational survey. Intensive Care Med. 2018;44(12):2079-90.

28. Poghosyan L, Clarke SP, Finlayson M, Aiken LH. Nurse burnout and quality of care: cross-national investigation in six countries. Res Nurs Health. 2010; 33(4):288-98.

29. Lim J, Bogossian F, Ahern K. Stress and coping in Singaporean nurses: a literature review. Nurs Health Sci. 2010;12(2):251-8.

30. Garczynski AM, Waldrop JS, Rupprecht EA, Grawitch MJ. Differentiation between work and nonwork self-aspects as a predictor of presenteeism and engagement: cross-cultural differences. J Occup Health Psychol. 2013;18(4):417.

31. Lu L, Cooper CL, Yen Lin H. A cross-cultural examination of presenteeism and supervisory support. Career Dev Int. 2013;18(5):440-56.

32. Parnell JA, Hatem T. Cultural antecedents of behavioural differences between American and Egyptian managers. J Manag Stud. 1999;36(3):399-418.

33. Herschbach P. Work-related stress specific to physicians and nurses working with cancer patients. J Psychosoc Oncol. 1992;10(2):79-99.

34. Morgeson FP, Humphrey SE. The work design questionnaire (WDQ): developing and validating a comprehensive measure for assessing job design and the nature of work. J Appl Psychol. 2006;91(6):1321.

35. Dallner M. Validation of the general Nordic questionnaire (QPSNordic) for psychological and social factors at work: Nordic Council of Ministers; 2000.

36. Hildebrandt V, Bongers P, Van Dijk F, Kemper H, Dul J. Dutch musculoskeletal questionnaire: description and basic qualities. Ergonomics. 2001:44(12):1038-55.

37. Siegrist J, Li J, Montano D. Psychometric properties of the effort-reward imbalance questionnaire. Germany: Duesseldorf University; 2014.

38. Li J, Yang W, Cheng Y, Siegrist J, Cho S-I. Effort-reward imbalance at work and job dissatisfaction in Chinese healthcare workers: a validation study. Int Arch Occup Environ Health. 2005;78(3):198-204.

39. Maslach C, Jackson SE, Leiter MP, Schaufeli WB, Schwab RL. Maslach burnout inventory: consulting psychologists: Press Palo Alto, CA; 1986.

40. Schwarzer R, Schmitz GS, Tang C. Teacher burnout in Hong Kong and Germany: a cross-cultural validation of the Maslach burnout inventory; 2000.

41. Watson R, Deary I, Thompson D, Li G. A study of stress and burnout in nursing students in Hong Kong: a questionnaire survey. Int J Nurs Stud. 2008;45(10):1534-42.

42. Fong TC-T, Ng S-M. Measuring engagement at work: validation of the Chinese version of the Utrecht work engagement scale. Int J Behav Med. 2012;19(3):391-7.

43. Wallston KA, Strudler Wallston B, DeVellis R. Development of the multidimensional health locus of control (MHLC) scales. Health Educ Monogr. 1978;6(1):160-70.

44. Wallston KA, Stein MJ, Smith CA. Form C of the MHLC scales: a conditionspecific measure of locus of control. J Pers Assess. 1994;63(3):534-53.

45. Maslach C, Jackson SE. The measurement of experienced burnout. J Organ Behav. 1981;2(2):99-113 
46. Scuffham PA, Vecchio N, Whiteford HA. Exploring the validity of HPQ-based presenteeism measures to estimate productivity losses in the health and education sectors. Med Decis Mak. 2014;34(1):127-37.

47. Lynn MR. Determination and quantification of content validity. Nurs Res. 1986;35(6):382-6.

48. Nunnally J. Psychometric theory. New York: McGraw-Hill; 1978.

49. Burke RJ, Greenglass ER. Effects of hospital restructuring on full time and part time nursing staff in Ontario. Int J Nurs Stud. 2000;37(2):163-71.

50. Gold MS, Bentler PM, Kim KH. A comparison of maximum-likelihood and asymptotically distribution-free methods of treating incomplete nonnormal data. Struct Equ Model. 2003;10(1):47-79.

51. Pournik O, Ghalichi L, Yazdi AT, Tabatabaee S, Ghaffari M, Vingard E. Reliability and validity of Persian version of World Health Organization Health and Work Performance Questionnaire in Iranian health care workers. Int J Occup Environ Med (The IJOEM). 2012;3(1 January):33-8.

52. Harrington D. Confirmatory factor analysis: Oxford University press; 2009.

53. Hu L, Bentler PM. Cutoff criteria for fit indexes in covariance structure analysis: conventional criteria versus new alternatives. Struct Equ Model Multidiscip J. 1999;6(1):1-55.

54. Watkins MP, Portney L. Foundations of clinical research: applications to practice. Upper Saddle River: Pearson/Prentice Hall; 2009.

55. Brown T. Confirmatory factor analysis for applied research. New York: Guilford; 2006

56. Caverley N, Cunningham JB, MacGregor JN. Sickness presenteeism, sickness absenteeism, and health following restructuring in a public service organization. J Manag Stud. 2007:44(2):304-19.

57. Böckerman P, Laukkanen E. What makes you work while you are sick? Evidence from a survey of workers. Eur J Pub Health. 2009;20(1):43-6.

58. McKevitt C, Morgan M, Dundas R, Holland W. Sickness absence and 'working through'illness: a comparison of two professional groups. J Public Health. 1997;19(3):295-300.

59. Fujimoto T, Kotani S, Suzuki R. Work-family conflict of nurses in Japan. J Clin Nurs. 2008:17(24):3286-95.

60. Kim $M$, Windsor C. Resilience and work-life balance in first-line nurse manager. Asian Nurs Res. 2015;9(1):21-7.

61. Leineweber C, Chungkham HS, Lindqvist R, Westerlund H, Runesdotter S, Alenius $L S$, et al. Nurses' practice environment and satisfaction with schedule flexibility is related to intention to leave due to dissatisfaction: a multi-country, multilevel study. Int J Nurs Stud. 2016;58:47-58.

\section{Publisher's Note}

Springer Nature remains neutral with regard to jurisdictional claims in published maps and institutional affiliations.

Ready to submit your research? Choose BMC and benefit from:

- fast, convenient online submission

- thorough peer review by experienced researchers in your field

- rapid publication on acceptance

- support for research data, including large and complex data types

- gold Open Access which fosters wider collaboration and increased citations

- maximum visibility for your research: over $100 \mathrm{M}$ website views per year

At $\mathrm{BMC}$, research is always in progress.

Learn more biomedcentral.com/submissions 